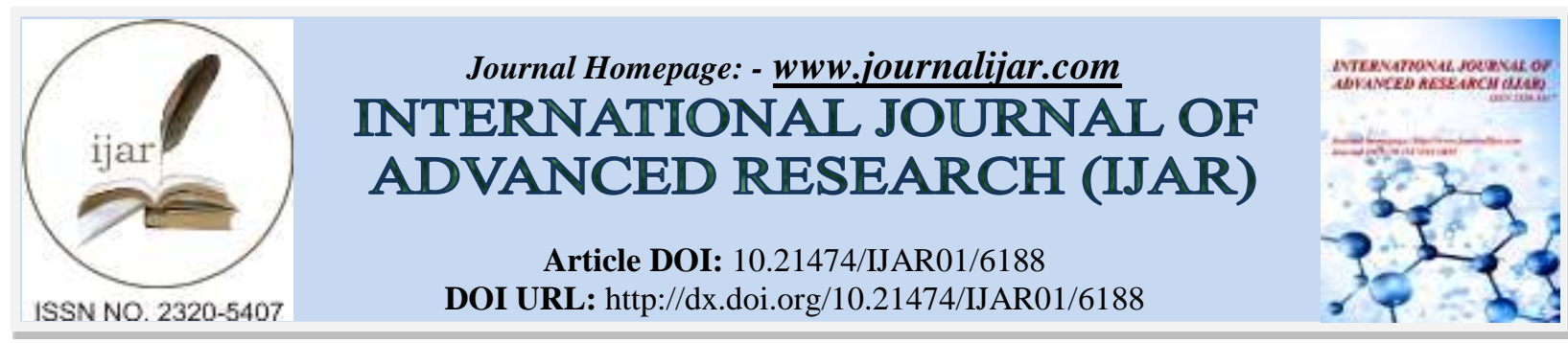

RESEARCH ARTICLE

\title{
IS IT NECESSARY TO SEND THE RESECTEDD STOMACH DURING LAPAROSCOPIC SLEEVE GASTRECTOMY FOR PATHOLOGICAL EXAMINATION?
}

Mohamed Ibrahim MD ${ }^{1}$, Ahmed Talha MD, MRCS ${ }^{1}$ and Hala Elmaghraby $\mathrm{PhD}^{2}$.

1. Department of Surgery, Medical Research Institute, Alexandria University, Egypt.

2. Department of Pathology, Medical Research Institute, Alexandria University, Egypt.

\section{Manuscript Info}

Manuscript History

Received: 02 November 2017

Final Accepted: 04 December 2017

Published: January 2018

Key words:-

Histopathology, Bariatric surgery, Obesity, Sleeve gastrectomy.

\section{Abstract}

Background: Laparoscopic sleeve gastrectomy (LSG) is the most commonly performed bariatric operation in Egypt. To the best of our experience there is no published data in Egypt regarding the results of Histopathological examination of the resected gastric specimen after LSG.

Objective: To find the range of gastric pathologies in the resected specimens and trying to answer the question whether the resected specimen after LSG should be sent for Histopathological examination or not?

Methods: Data were collected prospectively from the period from February 2014 till May 2017 and included 211 patients. LSG was performed by the bariatric team of our department using the same technique. The resected specimen was sent to the pathology department of our institute for pathological examination.

Results: the mean age of the studied patients was $36 \pm 11.8$ years with mean BMI of $44.1 \pm 4.7 \mathrm{Kg} / \mathrm{m}^{2}$, and female patients represents $67.8 \%$ of the studied patients. Chronic nonspecific gastritis was the most common Histopathological finding and was present in $52.1 \%$ of patients, normal histopathology was present in $25.6 \%$ of patients, and Helicobacter Pylori (HP) related gastritis was present in $19.9 \%$ of patients, gastrointestinal stromal tumor (GIST) was present in $4(1.9 \%)$ cases, and we have 1 case of healed cicatrized ulcer.

Conclusion: Benign lesions accounts for $98.1 \%$ of the studied patients signifying the non-importance of routine pathological examination of the resected specimen after LSG and should only be done in case of grossly suspected lesions. Preoperative esophagogastroduodenoscopy (EGD) may be advised before surgery.

Copy Right, IJAR, 2018,. All rights reserved.

\section{Introduction:-}

Morbid obesity is fast approaching tobacco as a preventable cause of death worldwide where more than 500 million adults are obese. [1] In Egypt the prevalence of obesity is fast increasing in comparison with other developing countries. [2- 4] 
Bariatric surgery is considered the most effective tool in management of obesity and its related comorbidities. [5] Laparoscopic sleeve gastrectomy (LSG) is a restrictive bariatric procedure, where more than $80 \%$ of the stomach is vertically resected including the fundus, is the most commonly performed bariatric operation in Egypt.

There is a controversy regarding the preoperative evaluation by esophagogastroduodenoscopy (EGD) before bariatric surgery with its implications on changing the planned procedure and with no definite guidelines regarding its use. [6- 8]

The number of published data regarding histopathological findings after LSG in the Arab world is scarce with low volume of cases. $[8,9]$ To the best of our experience there is no published data in Egypt regarding the results of pathological examination of the resected gastric specimen after LSG.

The aim of the present study is to find the range of gastric pathologies in the resected specimens in Egyptian patients who underwent LSG in our institute and trying to answer the question whether the resected specimen after LSG should be sent for Histopathological examination or not?

\section{Patients and Methods:-}

The study was conducted in the department of experimental and clinical surgery and the pathology department at the Medical Research Institute, University of Alexandria. The study was approved from the ethical committee of our institute and all patients signed an informed consent for Histopathological examination of the resected stomach.

Data were collected prospectively from the period from February 2014 till May 2017 and included 211 patients. LSG was performed by the bariatric team of our department using the same technique with gastric stapling over 36 Fr bougie with stable line reinforcement by sutures in all cases. The resected specimen was sent to the pathology department of our institute for pathological examination with proper marking of specific lesions if it was noticed during the operation.

Preoperative EGD was not performed routinely but only for symptomatic patients.

\section{Statistical Analysis:-}

Data were fed to the computer and analyzed using IBM SPSS software package version 20.0. (Armonk, NY: IBM Corp). The Kolmogorov- Smirnov, Shapiro and D'agstino tests were used to verify the normality of distribution of variables, Comparisons between groups for categorical variables were assessed using Chi-square test (Fisher or Monte Carlo). ANOVA was used to compare more than two groups for normally distributed quantitative variables and followed by Post Hoc test (Tukey) for pairwise comparison. Significance of the obtained results was judged at the $5 \%$ level.

\section{Results:-}

The present study included 211 patients who underwent LSG at our surgical department at the Medical Research Institute, University of Alexandria. Regarding patient's demography, female patients comprised $67.8 \%$ of the studied patients and the mean age of the studied patients was $36 \pm 11.8$ years with mean BMI of $44.1 \pm 4.7 \mathrm{Kg} / \mathrm{m}^{2}$ as depicted in (Table 1)

The Histopathological findings of the resected stomach sample was chronic non-specific gastritis in $52.1 \%$ of patients, normal (unremarkable histopathology) in $25.6 \%$ of patients, Helicobacter pylori (HP) related gastritis in $19.9 \%$ of patients, gastrointestinal stromal tumor (GIST) was present in $4(1.9 \%)$ cases, and we have 1 case of healed cicatrized ulcer (Table 2) (Figure I)

Whatever the type of gastritis we have encountered in the resected specimen it has no clinical implication on patients' postoperative course.

In the patient with the histopathology of healed cicatrized ulcer the gross lesion was present in the gastric antrum and it was about $1.5 \times 1 \mathrm{~cm}$ within the remaining pouch of the sleeve gastrectomy and was detected incidentally where we performed EGD during the operation and it revealed normal looking mucosa and we proceeded for mini gastric bypass with resection of the remaining stomach including the lesion for fear of being unfavorable pathology and the final biopsy was fourtionatly healed cicatrized ulcer. (Figure I) 
GIST was present in three $(1.42 \%)$ male patients and one $(0.47 \%)$ female patient with a mean age of $47.8 \pm 5$ years which is older than the mean age of the other studied patients but failed to reach a statistical significance (table 3 ). In two $(0.94 \%)$ cases, the gross lesion was present in the fundus, and the other two $(0.94 \%)$ cases the lesion was present in the anterior surface of the stomach at the mid body. (Figure II)

\section{Discussion:-}

In the present study, we are trying to find the spectrum of histopathological findings of the resected stomach among morbidly obese patients who underwent LSG in our institute and we think that this is the first study in Egypt that investigate the histopathology after LSG. Female patients represent $67.8 \%$ of the studied patients and this in agree with many other studies and this is explained by that female patients always try to have a slim body contour. [9- 11]

The most common histopathological finding in this study was chronic non-specific gastritis which was encountered in $52.1 \%$ of patients this agrees with a study published in Jordan [12]

And with other studies. [8, 10] this may raise a question about the relation between obesity and chronic gastritis. A study by Clapp [13] found that chronic gastritis was present in $44 \%$ of patients and this percent was reduced after the operation, even in patients who underwent Roux-en-Y Gastric bypass Czeczko et al [14] found that chronic gastritis decreased to a lower extent after the operation.

In contrast to our study, Makki et al [15] in a study on Saudi Arabian people found that chronic gastritis was present in $24 \%$ of patients also Miller et al [16] found that it was present in only $7.2 \%$ of the studied Australian patients and we don't know whether there is a geographical issue related to gastritis or not?

HP related gastritis was present in $19.9 \%$ of patients of this study which was not routinely screened out before the operation and this may be explained by the economic status of the patients. There is no correlation between BMI and HP infection as proved by a meta-analysis on 18 papers. [17] A study by Borg et al [18] agrees with our result in the incidence of HP related gastritis while it was much lower in Almazeedi et al [8] in comparison with this study.

Unremarkable Histopathological finding was present in about a quarter of the studied patients. A large cohort study formed in Qatar including 1555 patients found normal specimen in 52\% of patients [19], while a study by Ohanessian et al [20] from USA found normal specimen in $69 \%$. Ion the contrary no normal specimen was present in a study by Almazeedi et al [8] in Kuwait and by Firas et al [12] in Jordan and we think this is mostly due to ethnic issue.

GIST was present in $4(1.9 \%)$ cases in this study and the gross lesion was obviously seen during the bariatric procedure and found to be GIST on the final histopathology. Yuval et al [21] detect 5 cases of GIST among 827 patients, Almazeedi et al [8] has only 1 case of GIST among 656 patients, and a study by Enver Vardar et al [22] found that GIST has an incidence of $1.1 \%$ (in 2 out of 181 patients). On the contrary GIST was not present in many other studies. [23, 25]

Benign lesions accounts for $98.1 \%$ of the studied patients and this encourage the non-importance of routine histopathological examination of the resected specimen after LSG and should only be done in case of grossly suspected lesions.

The incidence of chronic gastritis in this study was $72 \%$ and this raise the importance of preoperative endoscopy and possibly treatment of HP preoperatively if possible although there is a debate about to perform preoperative endoscopy or not. [26]

We have higher incidence of GIST, more than 1\%, in this study than that published in literature [8, 21], and occurring in higher age groups. However, the tumor was completely resected and the postoperative period was well but we should deal with caution with these higher age groups. 


\section{Conclusion:-}

Benign lesions accounts for $98.1 \%$ of the studied patients signifying the non-importance of routine pathological examination of the resected specimen after LSG and should only be done in case of grossly suspected lesions. Preoperative EGD may be advised before surgery.

\section{Conflict Of Interest:-}

Authors stated that there is no conflict of interest.

Table (1):- Demographic data of studied patients

\begin{tabular}{|l|l|}
\hline Patient characteristics & No. $(\%)$ \\
\hline Sex & \\
\hline Male & $68(32.2 \%)$ \\
\hline Female & $143(67.8 \%)$ \\
\hline Age (years) & \\
\hline Median (Min. - Max.) & $35(18-60)$ \\
\hline Mean \pm SD. & $36 \pm 11.8$ \\
\hline BMI $\left(\mathbf{k g} / \mathbf{m}^{2}\right)$ & \\
\hline Median (Min. - Max.) & $44(35.6-62.4)$ \\
\hline Mean \pm SD. & $44.1 \pm 4.7$ \\
\hline
\end{tabular}

Table (2):- Histopathological findings

\begin{tabular}{|l|l|}
\hline Histopathological findings & No. $(\%)$ \\
\hline Chronic nonspecific gastritis & $110(52.1 \%)$ \\
\hline Normal & $54(25.6 \%)$ \\
\hline HP gastritis & $42(19.9 \%)$ \\
\hline GIST & $4(1.9 \%)$ \\
\hline Cicatrized ulcer & $1(0.5 \%)$ \\
\hline
\end{tabular}

Table (3):- distribution of Histopathological findings according to patients' demography

\begin{tabular}{|c|c|c|c|c|c|c|}
\hline & \multicolumn{5}{|c|}{ Histopathological findings } & \multirow{2}{*}{$\mathbf{p}$} \\
\hline & $\begin{array}{l}\text { Chronic nonspecific } \\
\text { gastritis } \\
(\mathbf{n}=110)\end{array}$ & $\begin{array}{l}\text { Normal } \\
(n=54)\end{array}$ & $\begin{array}{l}\text { HP gastritis } \\
(n=42)\end{array}$ & $\begin{array}{l}\text { GIST } \\
(n=4)\end{array}$ & $\begin{array}{l}\text { Cicatrized } \\
\text { ulcer } \\
(\mathbf{n}=\mathbf{1})\end{array}$ & \\
\hline \multicolumn{7}{|c|}{$(i 1-110)$} \\
\hline $\begin{array}{l}\text { Median } \\
\text { - Max.) }\end{array}$ & $33.5(18-58)$ & $38(18-60)$ & $35.5(18-60)$ & $48.5(41-53)$ & \multirow[t]{2}{*}{$55^{\#}$} & \multirow[t]{2}{*}{0.055} \\
\hline Mean \pm SD. & $34.1 \pm 34.1$ & $38 \pm 11.4$ & $36.7 \pm 12.9$ & $47.8 \pm 5$ & & \\
\hline \multicolumn{7}{|l|}{ BMI } \\
\hline $\begin{array}{l}\text { Median } \\
\text { - Max.) }\end{array}$ & $42.9(35.8-53.2)$ & $\begin{array}{l}44.3(36.8- \\
62.4)\end{array}$ & $\begin{array}{l}44.2(35.6- \\
52.1)\end{array}$ & $\begin{array}{l}43.4(39.8- \\
50.1)\end{array}$ & \multirow[t]{2}{*}{$49.1^{\#}$} & \multirow[t]{2}{*}{0.197} \\
\hline Mean \pm SD & $43.6 \pm 4.4$ & $45.2 \pm 5.3$ & $43.5 \pm 4.2$ & $44.2 \pm 4.4$ & & \\
\hline \multicolumn{7}{|l|}{ Gender } \\
\hline Male & $35(31.8 \%)$ & $17(31.5 \%)$ & $13(31.0 \%)$ & $3(75.0 \%)$ & $0(0.0 \%)$ & \multirow[t]{2}{*}{0.469} \\
\hline Female & $75(68.2 \%)$ & $37(68.5 \%)$ & $29(69.0 \%)$ & $1(25.0 \%)$ & $1(100.0 \%)$ & \\
\hline
\end{tabular}

\#: Excluded from the comparison due to small number of case $(n=1)$

*: Statistically significant at $\mathrm{p} \leq 0.05$ 


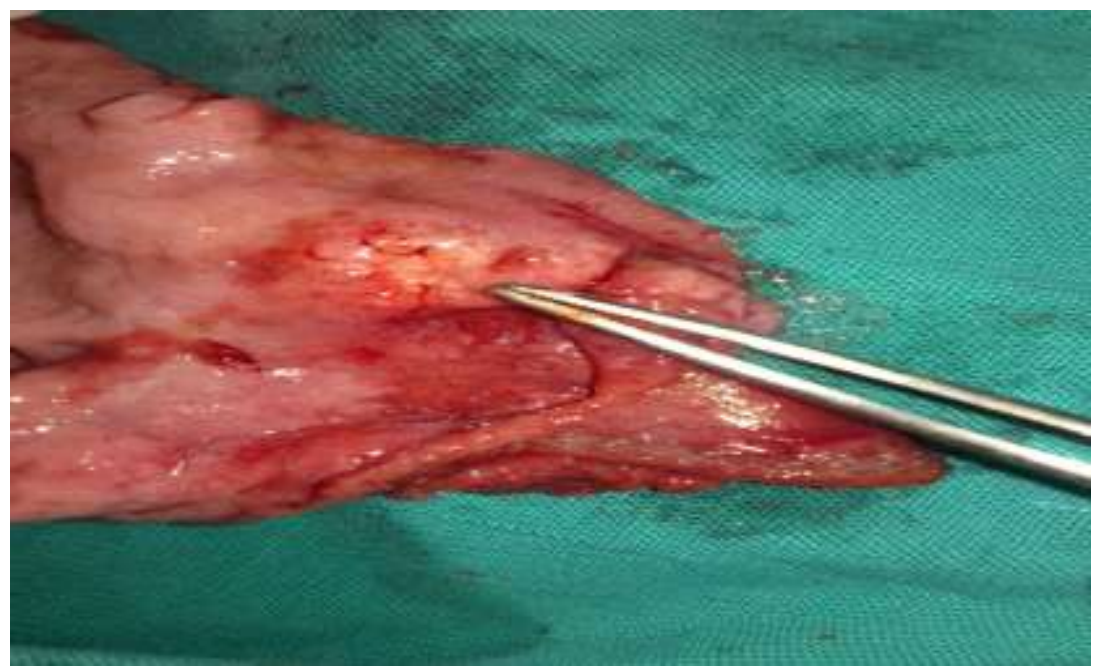

Figure I-: Healed cicatrized ulcer at gastric antrum

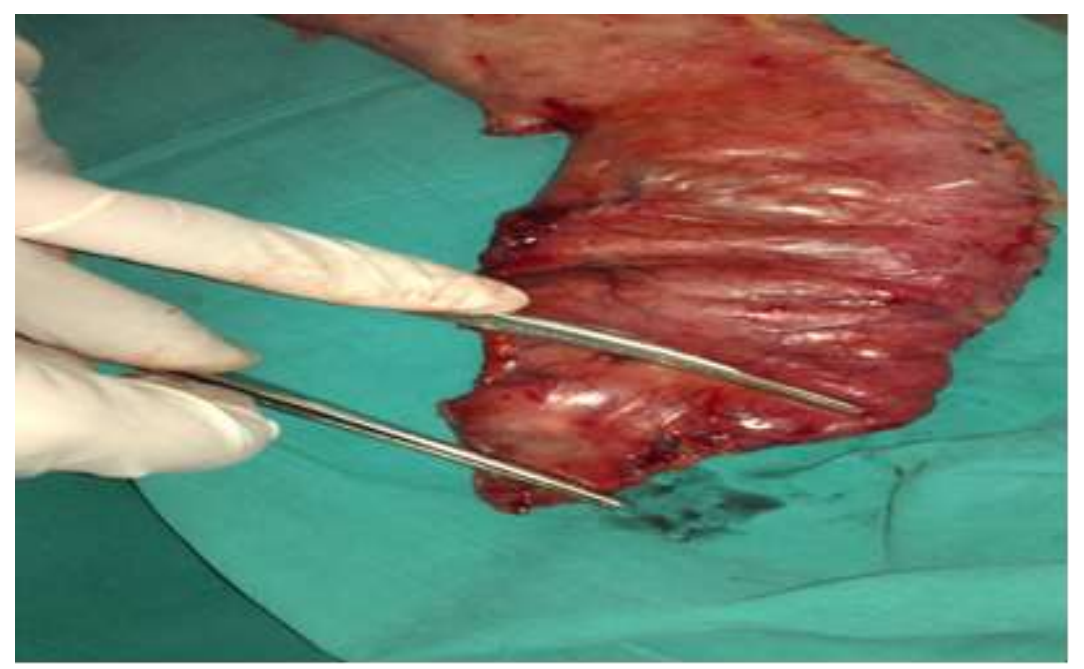

Figure II:- GIST at resected stomach

\section{References:-}

1. World Health Organization (2016). Obesity and overweight. [Cited 2016 August 15].

2. Mendez MA, Monteiro CA, Popkin BM. Overweight exceeds underweight among women in most developing countries. Am J Clin Nutr 2005;81(3):714-21.

3. Galal OM. The nutrition transition in Egypt: obesity, undernutrition and the food consumption context. Public Health Nutr 2002;5(A):141-8.

4. Egyptian demographic and health survey: Macro, International; 2005.

5. Buchwald H, Avidor Y, Braunwald E, Jensen MD, Pories W, Fahrbach K, et al. Bariatric surgery: A systematic review and meta-analysis. JAMA 2004; 292:1724-37.

6. De Moura Almeida A, Cotrim HP, Santos AS, Bitencourt AG, Barbosa DB, Lobo AP, et al. Preoperative upper gastrointestinal endoscopy in obese patients undergoing bariatric surgery: is it necessary? Surg Obes Relat Dis 2008; 4(2): 144-9.

7. Greenwald D. Preoperative gastrointestinal assessment before bariatric surgery. Gastroenterol Clin North Am 2010; 39(1): 81-6.

8. Almazeedi S, Al-Sabah S, Al-Mulla A, Al-Murad A, Al-Mossawi A, Al-Enezi K, et al. Gastric histopathologies in patients undergoing laparoscopic sleeve gastrectomies. Obes Surg 2013; 23:314-9.

9. Ahmed A. Histopathological Spectrum of Laproscopic Sleeve Gastrectomiesin King Fahd Hospitalofthe University, Alkhobar, Saudi Arabia. Khyber Med Univ J 2012; 4:39-44. 
10. Vrabie CD, Cojocaru M, Waller M, Sindelaru R, Copaescu C. The main histopathological gastric lesions in obese patients who underwent sleeve gastrectomy. Dicle Med J 2010; 37:97-103.

11. Almazeedi S, Al-Sabah S, Al-Mulla A, Al-Murad A, Al-Mossawi A, Al-Enezi $\mathrm{K}$, et al. Gastric histopathologies in patients undergoing laparoscopic sleeve gastrectomies. Obes Surg 2013; 23:314-9.

12. Firas W. Obeidat, Awni D. Shahait, Hiba A. Shanti, Hashem M. Al-Momani, Sami A. Abu Halaweh1. Histopathology results of Jordanian patients after laparoscopic sleeve gastrectomy. Saudi J Obesity 2015; 3:1820.

13. Clapp B. Histopathologic findings in the resected specimen of a sleeve gastrectomy. JSLS 2015;19: e2013.00259.

14. Czeczko LE, Cruz MA, Klostermann FC, et al. Correlation between pre-and postoperative upper digestive endoscopy in patients who underwent Roux-en-y gastrojejunal bypass. Arg Bras Cir Dig 2016; 29:33-7.

15. Makki AM, Aldaqal SM, Alorabi SH, et al. Chronic gastritis in morbidly obese patients with sleeve gastrectomy. Electron Physician 2016;8: 1786-90.

16. Miller GC, Reid AS, Brown IS. The pathological findings seen in laparoscopic sleeve gastrectomies for weight loss. Pathology 2016; 48:228-32.

17. John Danesh, Richard Peto (1998) Risk factors for coronary heart disease and infection with Helicobacter pylori: meta-analysis of 18 studies. BMJ 316: 1130-1132.

18. Borg CM, Elkalaaway A, Rotundo M, et al. Laparoscopic sleeve gastrectomy: Routine histological examination of the gastric remnant is highly recommended. Obes Surg. 2012; 22:1175.

19. Tamer Safaan, Moataz Bashah, Walid El Ansari, Mohsen Karam. Histopathological Changes in Laparoscopic Sleeve Gastrectomy Specimens: Prevalence, Risk Factors, and Value of Routine Histopathologic Examination. OBES SURG (2017) 27:1741-1749 DOI 10.1007/s11695-016-2525-1.

20. Ohanessian SE, Rogers AM, Karamchandan DM. Spectrum of gastric histopathologies in severely obese American patients undergoing sleeve gastrectomy. Obes Surg. 2016;26(3):595-602.

21. Yuval JB, Khalaileh A, Abu-Gazala M, Shachar Y, Keidar A, Mintz Y, et al. The true incidence of gastric GIST-a study based on morbidly obese patients undergoing sleeve gastrectomy. Obes Surg 2014;24(12):2134-7.

22. Enver Vardar, Ahmet Mücteba Öztürk, Didem Ersoz1, Erdem Comut1, Zehra Erkul1, Mehmet Yıldırım. Routine careful histopathological examination should be performed in sleeve gastrectomy specimens. Journal of Health Sciences 2017;7(1):44-49

23. Onzi TR, d'Acampora AJ, de Araújo FM, Baratieri R, Kremer G, Lyra HF Jr, et al. Gastric histopathology in laparoscopic sleeve gastrectomy: Pre-and post-operative comparison. Obes Surg 2014;24(3):371-6.

24. Raess PW, Baird-Howell M, Aggarwal R, Williams NN, Furth EE. Vertical sleeve gastrectomy specimens have a high prevalence of unexpected histopathologic findings requiring additional clinical management. Surg Obes Relat Dis 2015;11(5):1020-3.

25. Gündoğan M, Demirkan NÇ, Tekin K, Aybek H. Gastric histopathological findings and ghrelin expression in morbid obesity. Turk Pathol J 2013;29(1):19-26.

26. Zanotti D, Elkalaawy M, Hashemi M, et al. Current status of preoperative oesophago-gastro-duodenoscopy (OGD) in bariatric NHS units-a BOMSS survey. Obes Surg. 2016; 26(9):2257-62. doi:10.1007/s11695-0162304-z. 